\title{
The Effect of Comparison of BL 50 Cocoa Fat with Palm Oil (olein) on the Quality Characteristics of Produced Margarine
}

\author{
Srimaryati, Tuty Anggraini, and Anwar Kasim \\ Postgraduate Faculty of Agricultural Industrial Technology, Andalas University \\ e-mail: srimaryatibptpsumbar@gmail.com
}

\begin{abstract}
Cacao clone BL 50 (Balubuih Limapuluh Kota) is one of the local superior clones from West Sumatra. The fruit and bean size of BL 50 cocoa is bigger than other cacao. The fruit is oval in shape, maroon color when ripe and has a potential production of 3.69 tonnes / ha / year. The use of BL 50 cocoa beans is still limited to selling in the form of cocoa beans which are still mixed with other cacao, processed into cocoa powder and cocoa butter. Cocoa butter can be used to be processed into margarine mixed with palm oil. Margarine is processed by blending method. The purpose of this study was to determine the effect of the comparison of BL 50 cocoa butter with palm oil (olein) on the quality characteristics of margarine. This study used a completely randomized design with 5 treatment comparisons of BL 50 cocoa butter and palm oil (olein), namely: a. 80\%: 20\%, b. $75 \%: 25 \%$, c. $70 \%: 30 \%$, d. $65 \%: 35 \%$ and e. $60 \%: 40 \%$. The parameters observed included physical and chemical properties. Data were analyzed by using the $\mathrm{F}$ test and if significantly different, followed by Duncan's New Quotation Range Test (DNMRT) at the 5\% real level. The results of the analysis showed that selected margarine with a ratio of 60\% cocoa fat BL 50: 40 Palm oil (olein) with the analysis results in accordance with SNI 01-3541-2014 on margarine. The results of the analysis were water content of 11.46\%, iodine number $37.93 \mathrm{~g}$ iod / 100g, free fatty acids $0.72 \%$, acid number $1.43 \mathrm{mg} \mathrm{KOH} / \mathrm{g}$, fat content 83.27 , antioxidant activity 28.54 . \%, emulsion stability 85.95 and total plate number of $2.1 \times 104$ colonies.
\end{abstract}

\section{Keywords: BL 50 Cocoa Fat, palm oil, margarine, blending}

\section{INTRODUCTION}

The BL 50 (Balubuih Lima Puluh Kota) cocoa clone was released on April 21, 2017 as one of the local superior clones from West Sumatra. BL 50 is the result of farmer participatory selection. The fruit and bean size of the BL 50 cocoa is bigger than other cocoa. The fruit is oval in shape, maroon color when ripe and the potential for production reaches 3.69 tonnes / ha / year so it is highly recommended for cultivation [1].

As a new clone, in-depth information on its use into various other processed products has not been widely found. In West Sumatra, generally BL 50 cocoa is still sold raw in the form of beans or processed into cocoa butter and cocoa powder which are still mixed with other cocoa beans. Cocoa butter (cocoa butter) is a strategic cocoa product to be developed because it can create jobs, clear market opportunities and provide added value. Fat quality is not determined by taste but fat content. According to [2], cocoa butter generally contains $64.14 \%$ saturated fatty acids and $35.86 \%$ unsaturated fatty acids. Most types of saturated fatty acids in cocoa butter in general are stearic $(37.36 \%)$ and palmitic $(24.90 \%)$. While the most unsaturated fatty acids were Oleic at $33.17 \%$. This cocoa fat can be used as a raw material for various processed products, including margarine.

Margarine is a solid, semi-solid or liquid food product in the form of a water in oil (w / o) emulsion which is made from fat and / or vegetable oil and water. Margarine is made with or without the addition of other foodstuffs and permitted food additives [3]. [4] adding margarine is made with or without chemical changes including hydrogenation, interesterification and has gone through a refining process. According to SNI 01-35412002, in Indonesia there are three types of margarine, namely ready-to-eat margarine (table margarine and edible spread margarine), industrial margarine (used as raw material for food production) and cream or spread margarine (total fat content 62-78\%).

Margarine can be made by modifying fats and oils through three methods, namely Hydrogenation, Interesterification and Blending. The hydrogenation process involves the use of high temperatures, pressures and a catalyst (usually nickel). Interesterification is a 
reaction that converts triglyceride esters or fatty acid esters into other esters through reactions with an alcohol (alcoholysis), fatty acids (acidolysis) and transesterification. Blending is a method of modifying oil or fat which is easy and economical. Blending can be done by physically mixing two or more types of oil. Cocoa butter has a high melting point, the price is quite expensive, so we need another source of fat or other oil that is easily available with a lower melting point, namely palm oil (olein) which is relatively cheap. Margarine is made by forming an emulsion between the oil phase and the water phase using an emulsifier. The manufacturing process consists of several stages, namely fat formulation, mixing the oil and water phases, cooling to form texturing and tempering. The fat phase consists of fats or oils, flavors, fat soluble vitamins, dyes and emulsifiers while the water phase consists of water, salt, water soluble flavors, preservatives, citric acid and water soluble vitamins [5] [6].

\section{MATERIALS AND METHODS}

\subsection{Materials and Tools}

The raw materials used in this study were BL 50 clone cocoa butter obtained from the mini cocoa processing factory at the Agricultural Technology Park, Guguak District, Limapuluh Kota District, West Sumatra Province and packaged palm oil obtained in the market. In addition, several additives are used, such as salt, tween 80 and lecithin.

The chemicals used in this study were chloroform, methanol, $\mathrm{NaCl}, \mathrm{NaOH} 0.5 \mathrm{~N}, \mathrm{Na} 2 \mathrm{SO} 4,95 \%$ neutral alcohol, $0.1 \mathrm{~N}$ hexane $\mathrm{NaOH}, 0.2 \mathrm{~N} \mathrm{NaOH}$, pp indicator, azsaquades, KI $20 \%$, reagents. hanus, KI $15 \%$, sodium thiosulfate $0.1 \mathrm{~N}$, starch indicator $1 \%$, sterile salt and sodium benzoate.

The tools used for production include digital scales, measuring cups, beakers, mixers, stirring spoons, gas stoves, refrigerators, centrifuges, centrifuge tubes, plastic containers, spoons, water bath, electric stove, thermometer and mortar. Meanwhile, the tools used for chemical analysis are aluminum plates, ovens, gegep, desiccators, burettes, water baths, complete fat extraction equipment, vortices, pipette micrometers, 320 universal centrifuge, centrifuge tube, $250 \mathrm{ml}$ erlemeyer, $250 \mathrm{ml}$ erlemeyer, cup glass. $250 \mathrm{ml}$, measuring cup, funnel, dropper, spatula, stirring rod, thermometer, boiling stone, filter paper, aluminum foil, analytical scales, brook field texture analyzer.

\subsection{Determination of Margarine Formulation by mixing treatment with BL 50 Cocoa Fat and Palm Oil}

This study used a completely randomized design with 5 treatments and three replications. The treatments in this study were A. Cocoa butter BL 50: Palm oil (80: 20); B. Cocoa butter BL 50: Palm oil (75: 25); C. Cocoa butter BL 50: Palm oil (70: 30); D. Cocoa butter BL 50: Palm oil (65: 35) and E. Cocoa fat BL 50: Palm oil (60: 40). Data were analyzed by using the $\mathrm{F}$ test and if significantly different, followed by Duncan's New Quotation Range Test (DNMRT) at the 5\% real level.

The formulation used in the manufacture of margarine is the formulation of [7] which has been modified. The process of making margarine is mixing between the liquid phase, the oil phase and the emulsifier to form a w / o emulsion. The percentage of added additives in margarine production is calculated from the total cocoa butter and palm oil used. Stages in the manufacture of margarine BL 50 cocoa butter is liquefied at a temperature of $\pm 40^{\circ} \mathrm{C}$. Cocoa butter is mixed with fat or oil soluble ingredients such as palm oil, $0.5 \%$ lecithin and $0.25 \%$ tween 80 . To make the mixture more homogeneous, stir the mixture. with continuous stirring $( \pm$ 60 seconds). In another container, $16 \%$ water and $1 \%$ salt are mixed. After homogeneity, the oil phase and water phase are mixed. Stirring is carried out using a mixer at medium speed for 20 minutes at a temperature of $\pm 40^{\circ} \mathrm{C}$. Then the container is covered with cold water with a temperature range of $17-22^{\circ} \mathrm{C}$, stirring continuously until it forms an emulsion. The resulting margarine is packaged using a polypropylene (PP) cup container. Margarine is tempered at $5-7^{\circ} \mathrm{C}$ for $2 \times 24$ hours.

\section{RESULTS AND DISCUSSION}

The physical and chemical analyzes observed in blending cocoa butter BL 50 with palm oil (olein) were water content, iodine number, free fatty acid (FFA), fat content, antioxidant activity, emulsion stability, color and total plate number.

\subsection{Water content}

Water is a basic component in a food ingredient because water can affect the appearance, texture and taste of food. The water content in all types of food varies. The water content in food ingredients determines the acceptibility, freshness and durability of foodstuffs [8]. The results of the water content analysis of margarine by mixing BL 50 cocoa butter with palm oil (olein) can be seen in Figure 1. 


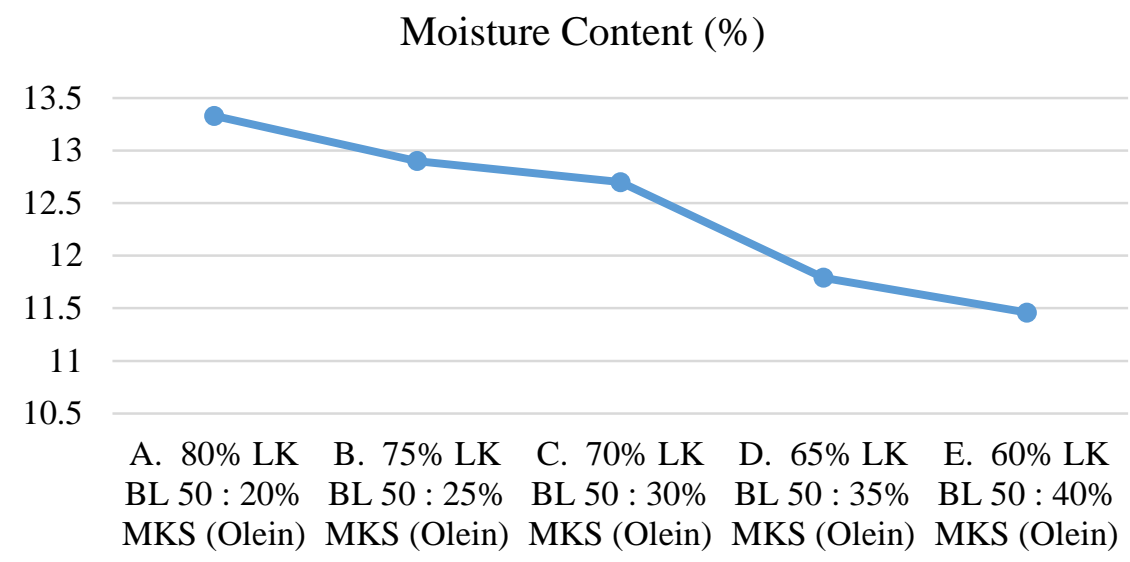

Note: $\mathrm{LK}=$ Cocoa Fat, MKS $=$ Palm Oil (olein)

Figure 1. Results of Analysis of Margarine Moisture Content

Based on Figure 1. It can be seen that the water content of the resulting margarine ranges from 11.46 $13.33 \%$. The greater the amount of palm oil added, the lower the moisture content of the resulting margarine. This occurs because the moisture content of the palm oil raw material is lower than BL 50 cocoa butter.

\subsection{Iod Numbers}

The iodine number is the chemical property of oil which is used to determine the degree of unsaturation of a fat and oil. Iodine compounds add double bonds to unsaturated fatty acids to form compounds with saturated bonds. The higher the iodine number, the more double bonds to add and the higher the degree of unsaturation of the oil or fat. The determination of the iodine number is done by adding excess iod to the sample. Excess iodine was titrated with Sodium Thio Sulfate to determine the amount of iodine used to add oil or fat [9]. Based on the results of analysis of variance on the iodine number of margarine, the number of double bonds or unsaturated bonds in oil has an effect on the iodine number of margarine. The results of the average iodine margarine number can be seen in Figure 2.

Value of Iod (g iod/100 g)

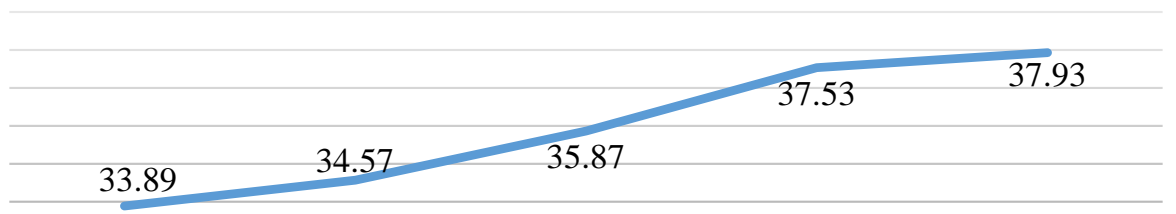

$\begin{array}{ccccccc}\text { A. } 80 \% \text { LK } & \text { B. } 75 \% \text { LK } & \text { C. } 70 \% \text { LK } & \text { D. } 65 \% \text { LK } & \text { E. } 60 \% \text { LK } \\ \text { BL 50:20\% } & \text { BL 50:25\% } & \text { BL 50:30\% } & \text { BL 50:35\% } & \text { BL 50:40\% } \\ \text { MKS (Olein) } & \text { MKS (Olein) } & \text { MKS (Olein) } & \text { MKS (Olein) } & \text { MKS (Olein) }\end{array}$

Note: $\mathrm{LK}=$ Cocoa Fat, MKS = Palm Oil

Figure 2. Results of Average Value of Iod Margarine Numbers

Based on Figure 2, it can be seen that the average iodine number of margarine is $33.89-37.93 \mathrm{~g}$ iod / $100 \mathrm{~g}$. The more palm oil is added, the higher the iodine number obtained. According to [10], the iodine number is the amount (gram) of iodine that can be bound by 100 grams of fat. The double bond in unsaturated fatty acids will react with iodine or iodine compounds. The iodine number represents the degree of unsaturation of fats and oils. The values of iodine numbers generated in this study are in accordance with those required in SNI 3748 (2009), which are in the range between $33-42 \mathrm{~g}$ iod / $100 \mathrm{~g}$. 


\subsection{Free Fatty Acids (FFA) and Acid Numbers}

One of the quality parameters of damage from oil or fat is the level of free fatty acids (FFA). High levels of free fatty acids indicate that the oil or fat has decreased in quality. [9] States that the levels of free fatty acids in oils and fats are an early indicator of oil and grease damage due to the hydrolysis process. The results of the average free fatty acid content of margarine and acid number can be seen in Figure 3.

Free Fatty Acids (FFA) and Acid Numbers

\begin{tabular}{llllll}
1.58 & & & & & \\
\hline
\end{tabular}

Note: $\mathrm{LK}=$ Cocoa Fat, MKS = Palm Oil (Olein)

Figure 3. Average Free Fatty Acids (FFA) and Acid Numbers

Based on Figure 3. The average value of the free fatty acid number (FFA) ranges from $0.72 \%-0.79 \%$. In the table, it can be seen that there is a tendency to decrease the value of the free fatty acid number (FFA). The level of free fatty acids (FFA) is directly proportional to the addition of palm oil (olein). The more palm oil you add, the lower the free fatty acid (FFA) value. The highest FFA value was found in treatment A 80\% Cocoa Fat BL 50: $20 \%$ palm oil (olein) and the lowest FFA value was found in treatment E 60\% Cocoa Fat BL 50: $40 \%$ palm oil (olein). This is also due to the fact that the free fatty acids from the BL 50 cocoa butter raw material are slightly higher than oil palm oil (olein). According to SNI 013541-2002 the maximum free fatty acid content in margarine is $2.56 \%$. In this study, the value of free fatty acids (FFA) produced was still below the SNI 01-35412002 limit.

The level of free fatty acids in oil is also influenced by high water content [8]. The water content in the oil will cause the hydrolysis process to occur and result in higher free fatty acid values. The value of free fatty acids from the results of this study was higher than the research [4] with fatty acid values of $0.87-1.18 \%$. This is due to differences in the oil raw materials used and the moisture content of the margarine products. The higher the water content value of margarine produced, the FFA value will increase.
According to [8] the level of free fatty acids contained in vegetable oils can be one of the parameters determining the quality of the oil. The amount of free fatty acids in oil is indicated by the value of the acid number. A high acid number indicates that the free fatty acids in vegetable oil are also high, so the quality of the oil is even lower. The acid number of margarine can be found by multiplying the FFA value by a factor. The value of the treatment acid number ranged from $1.43-1.58 \mathrm{mg} \mathrm{KOH} /$ g. This acid number still meets the SNI-01-3541-2002 standard regarding margarine, which is a maximum acid number of $4 \mathrm{mg} \mathrm{KOH} / \mathrm{g}$. The higher the acid number, the lower the quality of the oil or fat. According to [12] in [1] states that the acid number is a number that indicates the amount of free fatty acids contained in oil which is usually associated with the oil hydrolysis process which will affect the quality of the oil or fat.

\subsection{Fat level}

Fats and oils are non-polar ester compounds that are insoluble in water produced by plants and animals. Fats and oils have a very important function in food processing. Because fat is a non-polar ester, it dissolves in non-polar solvents such as N-hexane, petroleum ether, chloroform and benzene [9]. The average magarin fat produced can be seen in Figure 4. 
Fat $(\%)$

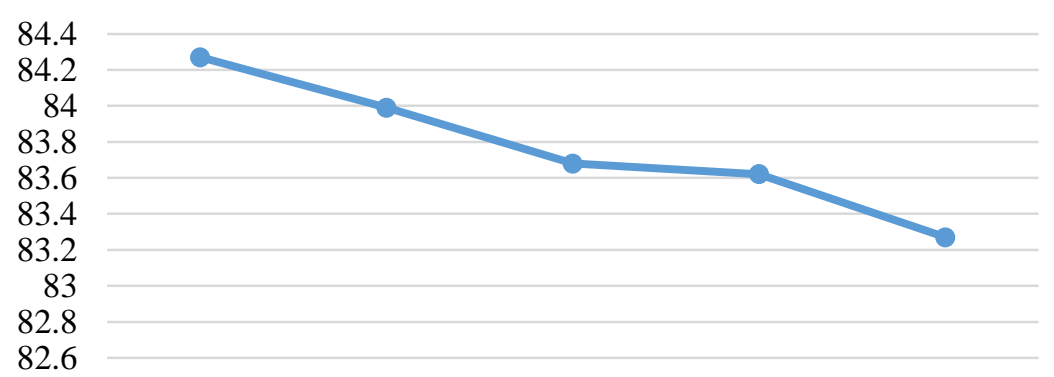

A. $80 \%$ LK B. $75 \%$ LK C. $70 \%$ LK D. $65 \%$ LK E. $60 \%$ LK BL $50: 20 \%$ BL $50: 25 \%$ BL $50: 30 \%$ BL $50: 35 \%$ BL $50: 40 \%$ MKS (Olein)MKS (Olein)MKS (Olein)MKS (Olein)MKS (Olein)

Note: $\mathrm{LK}=$ Cocoa Fat, MKS = Palm Oil

Figure 4. Average magarin fat

Figure 4 shows that the resulting magarin fat content ranges from $83.27-84.27 \%$. The greater the amount of BL 50 cocoa butter used in the manufacture of margarine, the greater the fat content. The high fat content in all treatments comes from the raw materials used which are mostly fats and oils, where more than $80 \%$ of the raw materials are fats and oils and the rest are water and water soluble materials. According to [8] Winarno (1991); Gunstone and Noriss (1983) stated that margarine is a semi-solid fat product which is an emulsion with a water in oil ( $w / o$ ) type, namely the water phase is in the oil phase, with the requirement that it contains not less than $80 \%$ fat, the rest is water and additives in the form of emulsifiers, preservatives, fragrances, dyes and antioxidants and vitamins.

The product fat content in all treatments met the SNI 01-3541-2014 standards, namely the required minimum fat content of $80 \%(\mathrm{w} / \mathrm{w})$. The results of the analysis of variance showed that the levels of magarin fat with the mixing treatment of cocoa butter and palm oil (olein) were not different at the significant level $\alpha=50 \%$.

\subsection{Antioxidant Activity}

Antioxidants are compounds or chemical components in certain amounts that can inhibit or slow down damage due to oxidative processes. Antioxidants are needed to protect the body from free radical attack (Sayuti and Rina, 2015). Andarwulan (1995) added that antioxidants are compounds that occur naturally in food ingredients. This compound serves to protect food from damage due to the oxidation reaction of fats or oils that cause food to taste and smell rancid. The results of the analysis of margarine antioxidant activity can be seen in Figure 5.

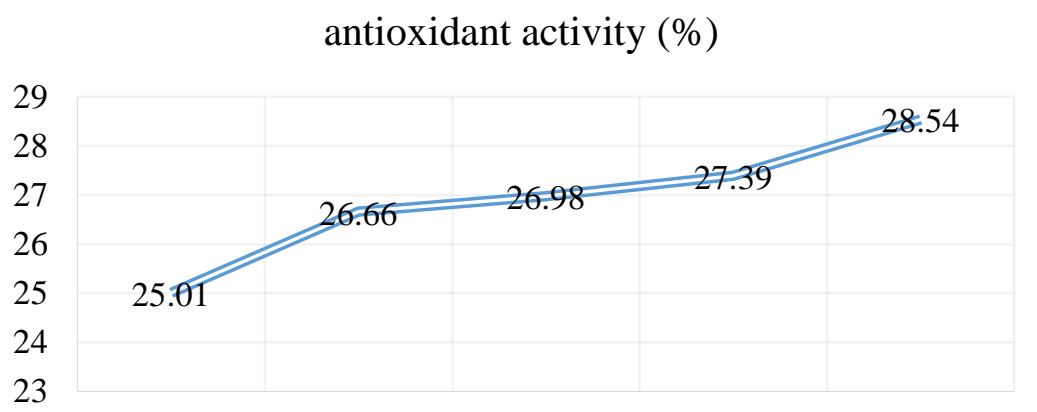

A. $80 \%$ LK B. $75 \%$ LK C. $70 \%$ LK D. $65 \%$ LKE. $60 \%$ LK BL $50: 20 \%$ BL $50: 25 \%$ BL $50: 30 \%$ BL $50: 35 \%$ BL $50: 40 \%$ MKS (Olein) MKS (Olein) MKS (Olein) MKS (Olein) MKS (Olein)

Note: $\mathrm{LK}=$ Cocoa Fat, MKS $=$ Palm Oil

Figure 5. Results of the analysis of margarine antioxidant activity 
From Figure 5 it can be seen that the antioxidant activity of the margarine produced ranges from 25.01 $28.54 \%$ at a concentration of $10,000 \mathrm{ppm}$. The more palm oil (olein) is added, the higher the antioxidant activity in the margarine. The antioxidants contained in margarine come from BL 50 cocoa butter and palm oil (olein).

\subsection{Emulsion Stability}

One of the emulsion product quality parameters is the emulsion stability. Emulsion stability is the resistance of the emulsion system in a product to maintain its stability under various conditions. Emulsion is small drops of a liquid that does not dissolve in other liquids. These two fluids are called the dispersed phase and the continuous phase. The emulsion system is inherently unstable because each particle has a tendency to combine with other particles. The strength and cohesiveness of the interfacial layer are important properties in emulsion formation.

A good emulsion is an emulsion that has a high level of consistency, in which it does not form layers and does not change color. The principle of emulsion stability is the balance between attractive and repulsive ndic forces between particles in the emulsion ndica. A stable emulsion system will be obtained if a stabilizer (emulsifier) which dissolves in the dominant phase is used. Emulsion stability in this study was determined by centrifuging margarine at a speed of $2700 \mathrm{rpm}$ for 10 minutes (Yasumutsu, 1972). The average result of emulsion stability can be seen in Figure 6 .

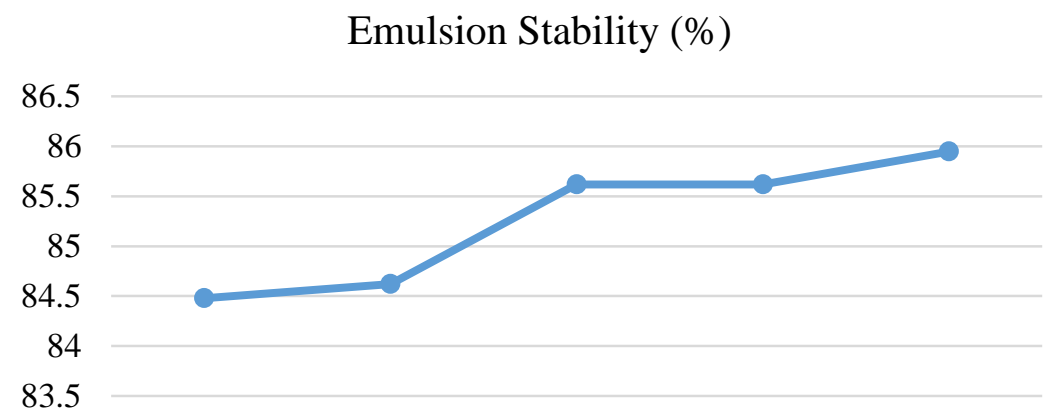

A. $80 \%$ LK B. $75 \%$ LK C. $70 \%$ LK D. $65 \%$ LKE. $60 \%$ LK BL $50: 20 \%$ BL $50: 25 \%$ BL $50: 30 \%$ BL $50: 35 \%$ BL $50: 40 \%$ MKS (Olein)MKS (Olein)MKS (Olein)MKS (Olein)MKS (Olein)

Note: $\mathrm{LK}=$ Cocoa Fat, MKS = Palm Oil

Figure 6. Results Average emulsion stability value of margarine

From Figure 6, it can be seen that the average value of margarine emulsion stability ranges from $84.48 \%$ $85.95 \%$. The more palm oil (olein) is added to margarine production, the emulsion stability value will increase. The resulting margarine has a fairly good viscosity, which is above $84 \%$. A stable (good) emulsion will not experience phase separation, color or consistency during settling.

Emulsion stability is also influenced by viscosity where the higher the viscosity of an emulsion system, the lower the average rate of deposition, consequently the resulting higher emulsion stability. The particle size will affect the emulsion stability. A large particle size will accelerate the movement of particles, due to the greater the chance of collisions between other particles so that the particles tend to combine into larger particles and eventually clump. This shows that the deposition rate is getting faster so that the emulsion is increasingly unstable (Dewi, 2011).

Temperature is also a factor affecting emulsion instability. The emulsion will break down if the temperature used for emulsion formation is greater than the optimal temperature. In general, the optimal emulsion temperature depends on the type of material contained in it (Petrowski, 1976).

\subsection{Total Plate Figures}

The total plate count (ALT) was observed to determine the content of microbial contaminants contained in the resulting margarine products. This observation is also carried out to determine the number of mesophyll aerobic bacteria that may contaminate a food product, drink, traditional medicine or cosmetics. Plate Count Agar (PCA) is the media used for the ALT test. Petri dishes containing cultures are reversed during the incubation period (Kusama, 2009). Fardiaz (1983) added that the results of microbiological analysis were reported using Standard Plate Count (SPC). The SPC explains how to count colonies on a plate and how to select existing data when calculating the number of colonies in the sample. 
The calculation of the total plate number of microorganisms is selected from petri dishes with the number of colonies between 30-300.This is because the media with high colony counts (> 300 colonies) are not validly counted so that the possibility of calculation errors is very large while the number for colonies is small $(<30$ colonies). Invalid calculated statistically. In determining this total plate number, the puor plate method was used for the number of bacterial colonies growing on the media to be counted after incubating at 37 oC for $2 \times 24$ hours (Mursalim, 2018).

The results of the analysis of total margarine plate numbers by mixing BL 50 cocoa butter with palm oil can be seen in Table 1 .

Table 1. The results of the analysis of total margarine plate numbers

\begin{tabular}{|c|c|}
\hline \multicolumn{1}{|c|}{ Treatment } & Total Plate Number (cfu /g) \\
\hline A. 80\% LK BL 50:20\% MKS (Olein) & $3,2 \times 10^{4}$ \\
\hline B. 75\% LK BL 50:25\% MKS (Olein) & $5,6 \times 10^{4}$ \\
\hline C. 70\% LK BL 50:30\% MKS (Olein) & $2,0 \times 10^{4}$ \\
\hline D. 65\% LK BL 50:35\% MKS (Olein) & $8,3 \times 10^{3}$ \\
\hline E. 60\% LK BL 50:40\% MKS (Olein) & $2,1 \times 10^{4}$ \\
\hline
\end{tabular}

Note: $\mathrm{LK}=$ Cocoa Fat, MKS = Palm Oil

From Table 1 it can be seen that the results of the analysis of total plate numbers of margarine by mixing $\mathrm{BL}$ 50 Cocoa butter with palm oil (olein) ranged from $8.3 \mathrm{x}$ 103 - 5.6 x 104. When compared with SNI 3541; 2014 regarding the quality of margarine The total plate count obtained, all the results of the total plate analysis of the processed margarine are still below the permitted total colony limit. This means that the resulting margarine products are safe for consumption.

The higher the total plate number, the more total microbes in the product. Ray (2000) states that microbiological quality deviations in food products can result in food products being unsuitable for marketing and consumption. Many studies show that consuming food products that deviate from their microbiological values or exceed the standard can cause diarrhea, dizziness, vomiting, nausea and fever. Even certain bacteria can cause fainting, nerve cell damage and death. Shewfelt (2014) adds that products with deviating microbiological standards will be more easily damaged so that their shelf life is shorter. In addition, microbiological quality is also used as an indicator of cleanliness and hygiene in the production process.

\section{CONCLUSION}

1. The E margarine formulation by mixing $60 \%$ cocoa butter BL 50 and $40 \%$ palm oil (olein) was selected based on SNI 01-3541-2014 on margarine and most preferred by panelists. The sensory test results from the panelists gave an average color rating of 4.2 , taste 3.2 , aroma 3.9 , spreadability 3.8 and texture 3.8 .
2. The physical and chemical quality characteristics of the selected margarine are water content of $11.46 \%$, iodine number $37.93 \mathrm{~g}$ iod / $100 \mathrm{~g}$, free fatty acid $0.72 \%$, acid number $1.43 \mathrm{mg} \mathrm{KOH} \mathrm{/} \mathrm{g,}$ fat content 83, 27, yellow color, $28.54 \%$ antioxidant activity at a concentration of 10,000 ppm, emulsion stability $85.95 \%$ and a total plate number of $2.1 \times 104$.

\section{SUGGESTION}

1. It is necessary to further apply the shelf life of the resulting margarine to the effect of natural dyes on the resistance of margarine products.

2. It is necessary to study the utilization of margarine for use as raw material for processed products such as cakes, pastries, bread and others.

\section{REFERENCES}

[1] Balitri Indonesian Industrial and Freshener Crops Research Institute. "Ministry of Agriculture. BL 50 Cocoa as Superior Variety from West Sumatra". http://perkebunan.litbang.pertanian.go.id/?p=18841. Accessed on 9 February 2018 at 11.38 WIB.

[2] Hilda, Leyla, "Making Low Calorie Cocoa Fat with Coconut Oil through an Interesterification Reaction". Mulawarman Journal of Chemistry 8 (1). 2010.

[3] [BSN] National Standardization Agency. Indonesian National Standard for Margarine SNI-3541: 2014. BSN. Jakarta, 2014. 
[4] Ramadhana, M.R. and J. Kusnadi. "Formulation of Margarine Product Development Made From Tuna Fish Oil (Thunnus sp) and Palm Oil Stearin". Journal of Food and Agroindustry, vol. 4, no. 2, pp. 525-535, 2016.

[5] Noraini, S and Y.K. Whoa. "Utilization of Palm and Palm Kernel Oils in Margarines and Other Emulsion Products”. 1994.

[6] Hasibuan, H.A. "Plastic Fat and Specialty Fat Based on Palm Oil and Palm Kernel Oil". Monograph. Medan Palm Oil Research Center. 2009.

[7] Hasibuan, H.A. and P. H. Aga. "Formulation and Processing of Margarine Using Palm Oil Fractions on a Small Industrial Scale and Its Application in Making Rolled Bolu”. AGRITECH, vol. 35, no. 4, 2015 .

[8] Winarno, F.G. "Food Chemistry and Nutrition". Jakarta. Gramedia Pustaka Utama. 2008.
[9] Kusnandar F. Food Chemistry for Macro Components. Jakarta: Dian Rakyat Publisher. 2010.

[10] Ketaren, S. Oil and Food Fats. UI-Pres. Jakarta. 2005.

[12] Raharjo, Slamet. Moh. Su'i and Suprihan. "The Effect of Addition of Turmeric Extract and Carrot Extract Dyes on Margarine Made From Coconut Oil and Brown Fat". Journal of Agricultural Sciences AGRICA, vol. 11, no. 2, 2017.

[13] Sayuti, Kesuma and R. "Yenrina. Natural and Synthetic Antioxidants". Padang. Andalas University Press. 2015.

[14] Yasumatsu, K., K. Sawada, S. Moritaka, M. Nfisaki, J. Toda, T. Wada and K. Ishi. "Whipping and Emulsifying Properties of Soybean Products". Agric. Biologist. Chem, vol. 36, pp. 719-727, 1972. 